\title{
Highly Porous Amorphous Calcium Phosphate for Drug Delivery and Bio-Medical Applications
}

\author{
Rui Sun ${ }^{1}$, Michelle Åhlén ${ }^{1}$, Cheuk-Wai Tai ${ }^{2}$, Éva G. Bajnóczi ${ }^{3}$, Fenne de Kleijne ${ }^{1}$, \\ Natalia Ferraz ${ }^{1}\left[\right.$, Ingmar Persson ${ }^{3}$, Maria Strømme ${ }^{1, *(1)}$ and Ocean Cheung $1, * \mathbb{C}$ \\ 1 Division of Nanotechnology and Functional Materials, Department of Engineering Sciences, Uppsala \\ University, SE-751 21 Uppsala, Sweden; rui.sun@angstrom.uu.se (R.S.); \\ michelle.ahlen@angstrom.uu.se (M.Å.); fenne.dekleijne@student.fontys.nl (F.d.K.); \\ natalia.ferraz@angstrom.uu.se (N.F.) \\ 2 Department of Materials and Environmental Chemistry, Stockholm University, SE-106 91 Stockholm, \\ Sweden; cheuk-wai.tai@mmk.su.se \\ 3 Department of Molecular Sciences, Swedish University of Agricultural Sciences, SE-750 07 Uppsala, Sweden; \\ eva.bajnoczi@slu.se (É.G.B.); ingmar.persson@slu.se (I.P.) \\ * Correspondence: maria.stromme@angstrom.uu.se (M.S.); ocean.cheung@angstrom.uu.se (O.C.)
}

Received: 28 November 2019; Accepted: 16 December 2019; Published: 19 December 2019

\begin{abstract}
Amorphous calcium phosphate (ACP) has shown significant effects on the biomineralization and promising applications in bio-medicine. However, the limited stability and porosity of ACP material restrict its practical applications. A storage stable highly porous ACP with Brunauer-Emmett-Teller surface area of over $400 \mathrm{~m}^{2} / \mathrm{g}$ was synthesized by introducing phosphoric acid to a methanol suspension containing amorphous calcium carbonate nanoparticles. Electron microscopy revealed that the porous ACP was constructed with aggregated ACP nanoparticles with dimensions of several nanometers. Large angle $X$-ray scattering revealed a short-range atomic order of $<20 \AA$ in the ACP nanoparticles. The synthesized ACP demonstrated long-term stability and did not crystallize even after storage for over 14 months in air. The stability of the ACP in water and an $\alpha$-MEM cell culture medium were also examined. The stability of ACP could be tuned by adjusting its chemical composition. The ACP synthesized in this work was cytocompatible and acted as drug carriers for the bisphosphonate drug alendronate (AL) in vitro. AL-loaded ACP released $\sim 25 \%$ of the loaded AL in the first 22 days. These properties make ACP a promising candidate material for potential application in biomedical fields such as drug delivery and bone healing.
\end{abstract}

Keywords: amorphous calcium phosphate; porous materials; cytocompatibility; drug carrier; bisphosphonate

\section{Introduction}

Calcium phosphate $(\mathrm{CaP})$ is a group of materials and minerals containing calcium and phosphate ions often with one or two additional inorganic ions such as hydroxide, fluoride, and carbonate. $\mathrm{CaP}$ is the main mineral component of bones and teeth in vertebrates and an important biomaterial that has been widely used in drug/protein delivery and bone regeneration due to its functionality and biocompatibility [1-3]. Amorphous calcium phosphate (ACP) is one of the polymorphs of CaP. $\mathrm{ACP}$ typically exists as an intermediate phase that forms during the precipitation of $\mathrm{CaP}$ and is known to be an essential precursor in the formation of bones in vertebrates [4-6]. ACP in its natural solid form typically comprises an assembly of ACP nanoparticles. ACP with specific surface area of up to around $300 \mathrm{~m}^{2} / \mathrm{g}$ has been reported previously [7]. ACP has been considered for drug delivery due to its high capacity for drug loading and controlled release [8,9]. In addition, ACP is bioactive, with 
better biodegradability than crystalline $\mathrm{CaP}$ and with the ability to promote osteoblast adhesion [10] and osteconductivity [11]. These properties make ACP a promising candidate material for bone regeneration [9,12-14], in applications such as bone cements [15] and bio-ceramics [16,17].

However, the potential applications of $\mathrm{ACP}$ have so far been limited by its instability. It quickly transforms to hydroapatite (HA) in aqueous solution, although this process is strongly affected by various factors, such as $\mathrm{pH}$, temperature, and presence of ions/additives in the solution. For example, the presence of $\mathrm{Mg}^{2+}, \mathrm{CO}_{3}{ }^{2-}$ (especially at levels of $4-6 \mathrm{wt} . \%$ in bone), $\mathrm{P}_{2} \mathrm{O}_{7}{ }^{4-}$ or $\mathrm{F}^{-}$ions and biological macromolecules can effectively stabilize ACP in biological systems $[18,19]$. Ion substitution $\left(\mathrm{Mg}^{2+}, \mathrm{CO}_{3}{ }^{2-}, \mathrm{Sr}^{2+}, \mathrm{Zn}^{2+}\right.$, etc. $)$ has also been widely used to stabilize synthetic ACP $[13,14,20,21]$. The carbonate ion has an excellent stabilizing effect on ACP as well [22]. Inclusion of carbonate ions in ACP would not only bring it closer to the components of bone but could also improve the biological behavior such as bioactivity and solubility, making the compound ideal for biomedical applications [20,23].

There are a number of ways to synthesize ACP. High supersaturation and a neutral/alkaline environment are typically needed regardless of the other synthesis conditions [24,25]. In a synthetic route in water, ACP is precipitated from a solution containing a high concentration of calcium and the phosphoric precursor [26]. However, the purity and components of ACP synthesized from aqueous solution are difficult to control because of the possible hydrolysis of phosphate ions and the presence of foreign ions. ACP precipitated from aqueous solution also appears to have a short lifetime [25,27]. In order to avoid hydrolysis, synthetic methods in organic solvents [28], including solvothermal synthesis $[7,29]$, have become popular in recent years. Organic solvents, i.e., alcohols, favor the formation of ACP because their lower dielectric constants than of water. This results in the ions in solution to be less solvated and consequence of decrease of the solubility and increase in supersaturation (also precipitation kinetics), which facilitates the amorphization [30-32].

Highly porous amorphous calcium carbonate (HPACC) has recently been developed by our laboratory [33]. It was obtained by drying a suspension of amorphous calcium carbonate (ACC) synthesized by dispersing calcium oxide in methanol under pressurized $\mathrm{CO}_{2}$ gas. This ACC suspension contained ACC nanoparticles with diameters $<10 \mathrm{~nm}$. The ACC suspension is stable and can be stored for several months at $0{ }^{\circ} \mathrm{C}$ before crystalline calcium carbonate is formed. In the present work, this ACC suspension was used as a source of $\mathrm{CaCO}_{3}$ in the synthesis of ACP. ACP can be formed from the reaction between calcium carbonate $\left(\mathrm{CaCO}_{3}\right)$ and phosphoric acid $\left(\mathrm{H}_{3} \mathrm{PO}_{4}\right)$ because of the relatively weak acidity of carbonic acid $\left(\mathrm{p} K_{\mathrm{a} 1}\left(\mathrm{H}_{2} \mathrm{CO}_{3}\right)=3.6\right)$ compared with phosphoric acid $\left(\mathrm{pK}_{\mathrm{a} 1}\left(\mathrm{H}_{3} \mathrm{PO}_{4}\right)=\right.$ 2.14) $[34,35]$. The carbonate content in the obtained ACP can be tailored by adjusting the ratio of $\mathrm{CaCO}_{3}$ to $\mathrm{H}_{3} \mathrm{PO}_{4}$ in the reaction mixture. On the other hand, the low cost of $\mathrm{CaCO}_{3}$ and $\mathrm{H}_{3} \mathrm{PO}_{4}$, and the room temperature synthesis facilitate the large-scale production of ACP materials.

We present a series of highly porous ACP compounds synthesized by introducing phosphoric acid into this ACC suspension in methanol at room temperature. The physico-chemical properties of the obtained ACPs were comprehensively characterized using a range of advanced techniques. Their stability in air condition, in an aqueous environment and in a cell culture medium was investigated as well. Mouse pre-osteoblastic cells were used to confirm the cytocompatibility of the synthesized ACPs. Finally, an anti-osteoporosis bisphosphonate drug—alendronate (AL)—was loaded into an $\mathrm{ACP}$ sample and the in vitro release of $\mathrm{AL}$ was monitored over time.

\section{Materials and Methods}

\subsection{Materials}

Calcium oxide ( $\mathrm{CaO}$, Reagent grade) was purchased from Alfa-Aesar (Kandel, Germany). Methanol (>99.8\%) was purchased from VWR (Radnor, PA, United States). $\mathrm{CO}_{2}(>99.998 \%$ ) was purchased from Air Liquide AB (Paris, France). Phosphoric acid (PA, $\geq 99.999 \%$ ), alendronate sodium (Pharmaceutical Secondary Standard), N-(2-Hydroxyethyl)piperazine-N'-(2-ethanesulfonic 
acid) (HEPES) aqueous solution (1 M, pH 7.0-7.6, sterile-filtered, BioReagent), dimethyl sulfoxide (DMSO) (sterile-filtered BioReagent $\geq 99.7 \%$ ), and the live/dead double staining kit were purchased from Sigma-Aldrich Sweden AB (Stockholm, Sweden). Gibco Dulbecco's phosphate-buffer saline (PBS), Gibco's Alpha Minimum Essential Medium with nucleosides without ascorbic acid ( $\alpha$-MEM), Invitrogen presto blue cell viability reagent and Gibco TrypLE Express enzyme were purchased from Thermo Fisher Scientific (Waltham, MA, USA). All chemicals were used without further purification.

\subsection{Synthesis of ACPs and $\mathrm{CaPs}$}

The ACP samples were synthesized by introducing varying amounts of phosphoric acid into the ACC suspension described in our previous study [33]. In a typical synthesis, $2.5 \mathrm{~g}$ of calcium oxide was added to $150 \mathrm{~mL}$ methanol at $50{ }^{\circ} \mathrm{C}$ under constant stirring in a glass reaction vessel (Andrew Glass Co Ltd., Vineland, NJ, USA). When the mixture appeared homogeneous, 4 bar $\mathrm{CO}_{2}$ was fed into the reaction vessel and the vessel was sealed. The mixture was left stirring at $50{ }^{\circ} \mathrm{C}$ for $4 \mathrm{~h}$. Thereafter, the pressure was released from the reaction vessel and the reaction mixture was centrifuged at $1357 \times g$ for $15 \mathrm{~min}$ to remove the unreacted calcium oxide. A suspension containing highly dispersed ACC nanoparticles of $<10 \mathrm{~nm}$ diameter (detailed in our previous study) [33] was obtained after centrifugation. This ACC suspension was used to prepare the ACP samples.

Phosphoric acid was first dissolved in methanol at a concentration of $58 \mathrm{mg} / \mathrm{mL}$. A series of phosphoric acid-methanol solutions were added to $30 \mathrm{~mL}$ ACC suspension $(\sim 25 \mathrm{mg}$ ACC nanoparticles $(\mathrm{mL}$ ) dropwise under vigorously stirring. The amount of phosphoric acid added ranged from $0 \mathrm{~g}, 0.32 \mathrm{~g}, 0.53 \mathrm{~g}, 0.58 \mathrm{~g}, 0.68 \mathrm{~g}, 0.78 \mathrm{~g}$ to $0.88 \mathrm{~g}$ per $30 \mathrm{~mL}$ ACC suspension. The obtained samples were named as ACC, ACP032, ACP053, CaP058, CaP068, CaP078 and CaP088, respectively. The prefix $\mathrm{ACP}$ refers to samples that were amorphous and $\mathrm{CaP}$ refers to samples that were crystalline (crystallinity is further discussed later). Porous ACC was acquired without adding phosphoric acid following the same method above. After stirring for $1 \mathrm{~h}$, the mixture was dried at $150{ }^{\circ} \mathrm{C}$ in a ventilated oven in order to evaporate the solvent. A translucent or white powder was obtained after solvent evaporation.

\subsection{Characterization}

Powder X-ray diffraction (PXRD) patterns were recorded using a Bruker D8 advance XRD Twin-Twin instrument (Bruker, Bremen, Germany) with $\mathrm{Cu}-\mathrm{K} \alpha$ radiation $(\lambda=0.15418 \mathrm{~nm})$, a step size of $0.04^{\circ}$ and $2 \mathrm{~s}$ per step in the $2 \theta$ range from 10 to $70^{\circ}$. The Infrared (IR) spectra were recorded using a Bruker Tensor 27 spectrometer (Bruker, Bremen, Germany) coupled with a platinum attenuated total reflection diamond sample stage. Raman spectroscopy experiments were carried out using a Renishaw inVia Qontor (Wotton-under-Edge, UK) Raman microscope. The sample was placed on a glass slide and exposed to frequency-doubled Nd:YAG lasers (wavelength $532 \mathrm{~nm}$ ) during data collection. Thermogravimetric analysis-differential scanning calorimetry (TGA-DSC) measurements were carried out using a Mettler Toledo TGA2 instrument (Schwerzenbach, Switzerland) in air with a flow rate of $40 \mathrm{~mL} / \mathrm{min}$ from room temperature to $900{ }^{\circ} \mathrm{C}$ at a heating rate of $10^{\circ} \mathrm{C} / \mathrm{min}$. Inductively coupled plasma-optical emission spectroscopy (ICP-OES) measurements were conducted using a Vista-MPX CCD Simultaneous ICP-OES instrument (Varian Inc., Palo Alto, CA, USA). X-ray photoelectron spectroscopy (XPS) experiments were conducted on a PHI Quantera II scanning XPS microprobe (Chanhassen, NM, USA). A full spectrum along with energy-resolved spectra for $\mathrm{C} 1 \mathrm{~s}, \mathrm{O} 1 \mathrm{~s}$ and $\mathrm{Ca}$ $2 \mathrm{p}$ or P $2 \mathrm{p}$. The spectra were calibrated against the $\mathrm{C} 1 \mathrm{~s}$ peak at $284.8 \mathrm{eV}$ for adventitious carbon. Scanning electron microscope (SEM) images were recorded using a Zeiss LEO 1530 scanning electron microscope (Oberkochen, Germany) operating at $2 \mathrm{kV}$. The samples were coated with a layer of gold-palladium to avoid the charging effect. Transmission electron microscope (TEM) images were acquired by a 200 kV JEOL JEM-2100F (JEOL Ltd., Akishima, Japan) equipped with a Schottky-type field emission gun and a bottom mounted Gatan Ultrascan camera (Gatan Inc., Pleasanton, CA, USA). Bright field (BF)- and high-angle annular dark-field (HAADF)-scanning TEM (STEM) images were 
simultaneously recorded by a Gatan BF detector and JEOL ADF detector, respectively. The samples were dispersed onto $\mathrm{Cu}$ TEM grids with carbon supporting films and dried in air. Large angle X-ray scattering (LAXS) experiments were carried out using a custom-made large-angle $\theta-\theta$ goniometer with MoK $\alpha$ radiation $(\lambda=0.71073 \AA)$, detailed elsewhere [33]. $N_{2}$ adsorption measurements were carried out in a Micromeritics ASAP 2020 (Norcross, GA, USA) volumetric gas adsorption analyzer. Prior to the adsorption measurements, the sample was degassed at $100{ }^{\circ} \mathrm{C}$ for $6 \mathrm{~h}$ under dynamic vacuum $\left(1 \times 10^{-4} \mathrm{~Pa}\right)$ using a Micromeritics Smart VacPrep060 (Norcross, GA, USA) sample preparation unit. The procedures for the cell study, drug loading and in vitro drug release are detailed in the Supporting Information.

\section{Results and Discussion}

\subsection{Synthesis and Characterization of ACPs and CaPs}

We synthesized ACPs by introducing from 0.32 to $0.88 \mathrm{~g}$ of phosphoric acid to a $30 \mathrm{~mL}$ ACC suspension in methanol (with an estimated solid ACC content of $\sim 25 \mathrm{~g} / \mathrm{mL}$ ). ACP nanoparticles in a suspension in methanol were subsequently obtained based on the reaction between the ACC nanoparticles and phosphoric acid. ACP nanoparticles aggregated randomly to form porous ACP when the solvent (methanol) was evaporated through a drying process. The obtained ACPs were characterized by various characterization techniques.

PXRD patterns (Figure 1a) showed that ACC, ACP032, and ACP053 (synthesized with relatively low amount of phosphoric acid) had no diffraction peaks in their X-ray diffractograms. We therefore considered these samples as X-ray amorphous (simply referred to as "amorphous" in the discussion). When the amount of phosphoric acid was further increased (from 0.58 to $0.68 \mathrm{~g} / 30 \mathrm{~mL}$ ACC suspension), X-ray diffraction peaks related to calcium hydrogen phosphate $\left(\mathrm{CaHPO}_{4}\right)$ were observed. Here, we used "CaP" to indicate the crystalline state of the samples (i.e., CaP058, CaP068). On these samples, calcite was also detected (the diffraction peaks of calcite are marked with an asterisk $\left(^{*}\right)$ in Figure $1 \mathrm{~b}$ at around $2 \theta=29.6^{\circ}$ ). The formation of calcite was probably related to the formation of water as a product of the reaction between calcium carbonate and phosphoric acid-since water can induce the crystallization of ACC to calcite. When the amount of phosphoric acid was further increased (CaP078, CaP088), the diffraction peaks of $\mathrm{CaHPO}_{4}$ increased in intensity. The crystallinity of the $\mathrm{CaP}$ samples (CaP058, CaP068, CaP078 and CaP088) increased with increasing amounts of phosphoric acid added to the ACC suspension. On the other hand, the diffraction peaks related to calcite decreased in intensity with an increasing amount of phosphoric acid. The crystalline $\mathrm{CaHPO}_{4}$ phase was verified to be mainly monetite (PDF 00-009-0080) (Figure $1 \mathrm{~b}$ and Figure S1).

IR spectra of ACC, and the ACPs and CaPs are presented in Figure 1c. ACP032 displayed the characteristic IR bands of ACC ( $v_{3}$ bands at $1414 \mathrm{~cm}^{-1}$ and $1484 \mathrm{~cm}^{-1}, v_{1}$ band at $\left.1074 \mathrm{~cm}^{-1}\right)$ as well as broad bands associated with ACP $\left(v_{3}\right.$ at $1028 \mathrm{~cm}^{-1}$ with a shoulder at $\sim 1072 \mathrm{~cm}^{-1}, v_{4}$ centered at $\sim 570 \mathrm{~cm}^{-1}$ ) [25]. The broad IR bands confirmed that ACP existed in an amorphous state in ACP032, as crystalline CaP would show relatively sharp IR bands. The IR bands associated with ACC were not detected for ACP053, but the characteristic broad-bands associated with ACP were still present. When the amount of phosphoric acid was increased further, the IR bands associated with crystalline CaP $\left(\mathrm{CaHPO}_{4}\right.$, monetite) became increasingly defined, as observed in the IR spectra for CaP058, CaP068, CaP078, and CaP088. Several sharp $v_{4}$ bands were noted between 480 and $590 \mathrm{~cm}^{-1}$ as well as two sharp $v_{3}$ bands between 1055 and $1125 \mathrm{~cm}^{-1}$. The $v_{1}$ vibration band at around $995 \mathrm{~cm}^{-1}$ also appeared in the CaP068, CaP078, and CaP088 spectra. The very weak band at $1086 \mathrm{~cm}^{-1}$ and $879 \mathrm{~cm}^{-1}$ in the spectrum of CaP068 may be associated with the $v_{1}$ and $v_{3}$ bands of calcite. No IR bands associated with ACC/calcite were clearly detected in the CaP058, CaP078, and CaP088 spectra. 

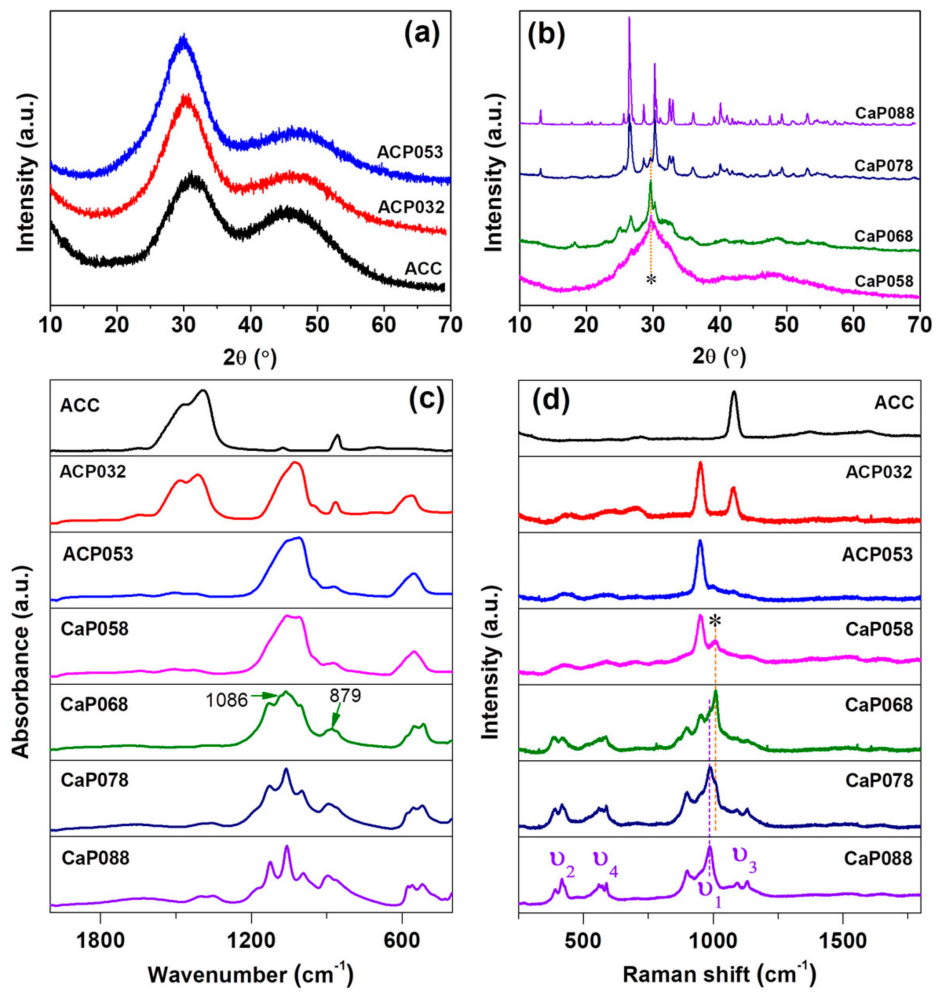

Figure 1. Powder X-ray diffraction (PXRD) for calcium phosphate formed by the addition of increasing amounts of phosphoric acid to amorphous calcium carbonate (ACC) suspension. (a) amorphous calcium phosphate (ACP) samples formed with low phosphoric acid amounts and (b) crystalline CaP samples formed with higher amounts; (c) Infrared (IR) spectra and (d) Raman spectra for ACP and crystalline CaP samples compared with ACC.

The Raman spectra of ACC, and of the ACP and CaP samples are shown in Figure 1d. The Raman spectrum of ACP032 had two distinct bands: one at $\sim 1100 \mathrm{~cm}^{-1}$, which corresponded to the $v_{1}$ vibration of the carbonate ion $\left(\mathrm{CO}_{3}{ }^{2-}\right)$, and one at $\sim 950 \mathrm{~cm}^{-1}$, which corresponded to the $v_{1}$ vibration of the phosphate ion $\left(\mathrm{PO}_{4}{ }^{3-}\right)$. In the Raman spectrum of ACP032, other vibration bands $\left(v_{2}, v_{3}\right.$ and $v_{4}$ ) typically observed in crystalline $\mathrm{CaP}$ had very low intensities and could not be easily identified. The broad $v_{1}$ and lack of the crystalline CaP Raman bands further confirmed the amorphous state of ACP032. The Raman spectrum of ACP053 had similar bands, associated with $\mathrm{PO}_{4}{ }^{3-}$, to those seen in $\mathrm{ACP} 032$. However, the $v_{1}$ band of $\mathrm{CO}_{3}{ }^{2-}$ was not observed because of the reduced carbonate content. For $\mathrm{CaP068}, \mathrm{CaP} 078$, and $\mathrm{CaP} 088$, the Raman bands associated with crystalline $\mathrm{CaP}\left(\mathrm{CaHPO}_{4}\right.$, monetite) were distinct and clearly observed. In addition to the $v_{1}$ band at around $\sim 987 \mathrm{~cm}^{-1}$, the $v_{2}\left(\sim 380-430 \mathrm{~cm}^{-1}\right), v_{3}$ (at around $\sim 1092$ and $\left.1129 \mathrm{~cm}^{-1}\right)$, and $v_{4}\left(\sim 540-610 \mathrm{~cm}^{-1}\right)$ bands were clearly observed for these samples [36-38]. The Raman bands marked with asterisk $\left.{ }^{*}\right)$ could be attributed to the small amount of calcite in CaP058, CaP068 and CaP078, which was coincident with the PXRD results (Figure 1b).

We further analyzed the ACPs and CaPs using TGA-DSC. The TGA curves for ACP032, ACP053, and CaP058 are shown in Figure 2a (TGA-DSC curves for the other CaPs can be found in Figure S2 in the Supporting Information). The TGA curves of ACP032 indicated two obvious mass losses. The first was related to the evaporation of adsorbed species and structural water below $\sim 500{ }^{\circ} \mathrm{C}$. The second that occurred at $\sim 750^{\circ} \mathrm{C}$ (Figure 2a) was related to the decomposition of crystalline calcium carbonate (formed by heating ACC) in ACP032. The carbonate content of ACP032 was calculated to be around 15 wt.\% (Figure S3) according to the mass drop between $600{ }^{\circ} \mathrm{C}$ and $800{ }^{\circ} \mathrm{C}$ in the TGA curve of ACP032. The presence of carbonate in as-synthesized ACP032 was further investigated by ICP-OES (Table 1) and XPS (Figure S4). The composition of ACP032 from ICP-OES suggested that it contained about 
16 wt.\% carbonate, which was coincident with the value calculated from TGA. The TGA curves for ACP053 and CaP058 showed a gradual decrease in mass up to $\sim 500{ }^{\circ} \mathrm{C}$; this mass loss was related to the removal of adsorbed and structural water (and condensation reaction of $\mathrm{CaHPO}_{4}$ in $\mathrm{CaP} 058$, which was also observed in $\mathrm{CaP068}, \mathrm{CaP} 078$, and CaP088, as discussed later) [39]. No mass drop related to the decomposition of calcium carbonate was observed for ACP053 and CaP058. The data from ICP-OES (Table 1) suggested that ACP053 contained a small amount ( 4 wt.\%) of carbonate. The presence of a small amount of carbonate is typical for ACP and CaP materials and has been reported previously in literature [28,36,40-42]. It is worth noting that the content of carbonate ions in ACP053 was similar to that in human bone [43]. The different carbonate content in ACP032 and ACP053 also suggests that the carbonate constitution in ACP materials could be easily adjusted with this method. A small exothermal peak at about $700{ }^{\circ} \mathrm{C}$, related to the phase transformation/crystallization of $\mathrm{ACP}$, was observed in the DSC heat-flow curves of ACP053 and CaP058 (Figure 2b) [44,45]. This exothermic peak shifted from $700{ }^{\circ} \mathrm{C}$ in ACP053 to $694{ }^{\circ} \mathrm{C}$ in CaP058. This shift may be related to the low level of crystallinity present in the as-synthesized CaP058 (Figure 1b). The presence of small crystallites may have favored the further crystallization of ACP to CaP.
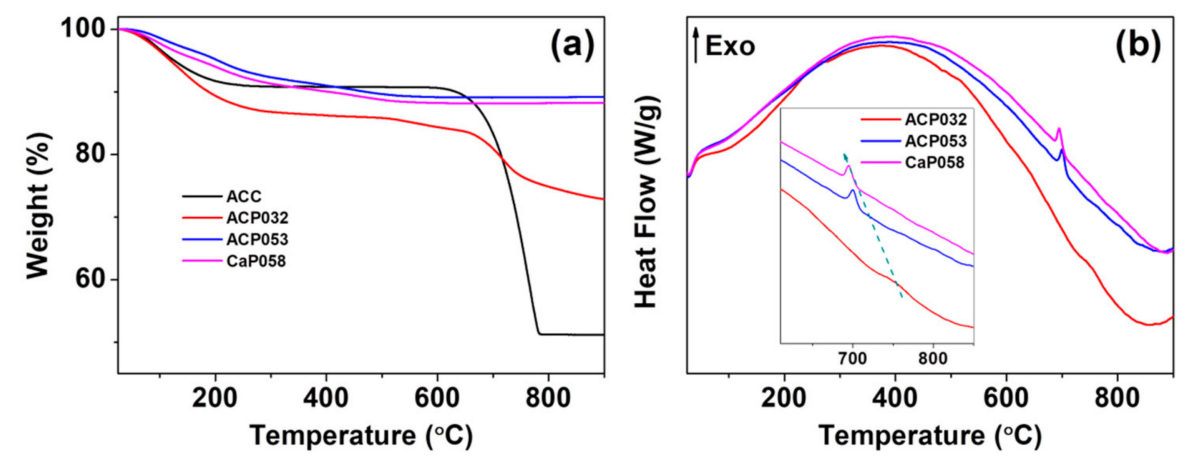

Figure 2. (a) Thermogravimetric analysis (TGA) and (b) the corresponding differential scanning calorimetry (DSC) heat-flow curves for the amorphous calcium phosphate samples ACP032 and ACP053 and the crystalline calcium phosphate sample CaP058.

Table 1. Inductively coupled plasma-optical emission spectroscopy (ICP-OES) analysis of the element content in the amorphous calcium phosphate samples ACP053 and ACP032.

\begin{tabular}{ccccccc}
\hline & $\mathbf{C}$ & $\mathbf{H}$ & $\mathbf{C a}$ & $\mathbf{P}$ & $\mathbf{C a} / \mathbf{P}$ & Estimated Carbonate Content (wt.\%) \\
\hline ACP032 & 0.26 & 1.56 & 0.84 & 0.38 & $\mathbf{2 . 2 1}$ & $\sim \mathbf{1 6 \%}$ \\
ACP053 & 0.07 & 1.73 & 0.86 & 0.56 & $\mathbf{1 . 5 3}$ & $\sim 4 \%$ \\
\hline
\end{tabular}

The TGA curves of CaP068, CaP078, and CaP088 (Figure S2) showed that, apart from evaporation of adsorbed or structure water, there was a clear mass loss between 300 and $500{ }^{\circ} \mathrm{C}$; the magnitude of the mass loss increased with increased crystallinity in the CaP samples. This mass loss was attributed to the condensation reaction of monetite (i.e., $\mathrm{CaHPO}_{4}$ ) [39]. Differences in the TGA-DSC analysis of CaP068, CaP078 and CaP088 are presented and discussed further in Figure S2 in the Supporting Information.

The porosity of the ACPs and CaPs was analyzed using $\mathrm{N}_{2}$ sorption; the results are summarized in Table 2. The Brunauer-Emmett-Teller (BET) surface areas of ACP032 and ACP053 (the synthesis of which was based on the synthesis of HPACC [33]) were higher than those of all the other tested samples, and higher than that of HPACC in our previous study. Specifically, ACP053 had the highest BET surface area $\left(418 \mathrm{~m}^{2} / \mathrm{g}\right)$ of all the forms of CaP (both amorphous and crystalline) reported in the literature [7,28,46-48], to the best of our knowledge (as ACP032 contained around 16 wt.\% of carbonate, it was not considered a high purity ACP). A comparison between the porosity of the ACPs synthesized in this work and that of the ACPs reported in the literature is listed in Table S1. The $\mathrm{N}_{2}$ adsorption/desorption isotherm and the density functional theory (DFT) pore-size distribution for 
ACP053 are shown in Figure 3a,b $\left(\mathrm{N}_{2}\right.$ sorption isotherms and the DFT pore-size distribution curves for other samples can be found in the Supporting Information, Figure S5).

Table 2. Porosity of ACP and crystalline CaP samples synthesized in this work.

\begin{tabular}{|c|c|c|c|c|c|}
\hline Samples & $\begin{array}{l}\text { Brunauer-Emmett-Teller } \\
\text { (BET) Surface Area }\left(\mathrm{m}^{2} / \mathrm{g}\right)\end{array}$ & $\begin{array}{l}\text { Peak Pore-Size } \\
\quad \text { a }(\mathrm{nm})\end{array}$ & $\begin{array}{l}\text { Pore Volume } \\
\quad\left(\mathrm{cm}^{3} / \mathrm{g}\right)\end{array}$ & $\begin{array}{l}\text { Density } \\
\left(\mathrm{g} / \mathrm{cm}^{3}\right)^{\mathrm{c}}\end{array}$ & $\begin{array}{l}\text { Calculated Particle } \\
\text { Size }^{d}(\mathrm{~nm})\end{array}$ \\
\hline АCP032 & 423 & 5.4 & 0.57 & 2.49 & 5.7 \\
\hline АCР053 & 418 & 9.3 & 1.05 & 2.59 & 5.6 \\
\hline CaP058 & 294 & 18.6 & 1.39 & 2.61 & 7.8 \\
\hline CaP068 & 133 & 18.6 & 0.62 & 2.70 & 16.7 \\
\hline CaP078 & 52 & 6.8 & 0.11 & - & - \\
\hline CaP088 & 6 & 18.6 & 0.10 & - & - \\
\hline
\end{tabular}

(a) peak pore-size distribution was calculated by using the density functional theory (DFT) to the adsorption points using the $\mathrm{N}_{2}$ slit pore model; (b) pore volume was taken at the last adsorption point at relative pressure $\sim 0.98$; (c) density of samples was obtained by He pycnometry; (d) particle size was calculated by Brunauer-Emmett-Tell (BET) surface area and density of sample (modelled with non-porous spherical particles).
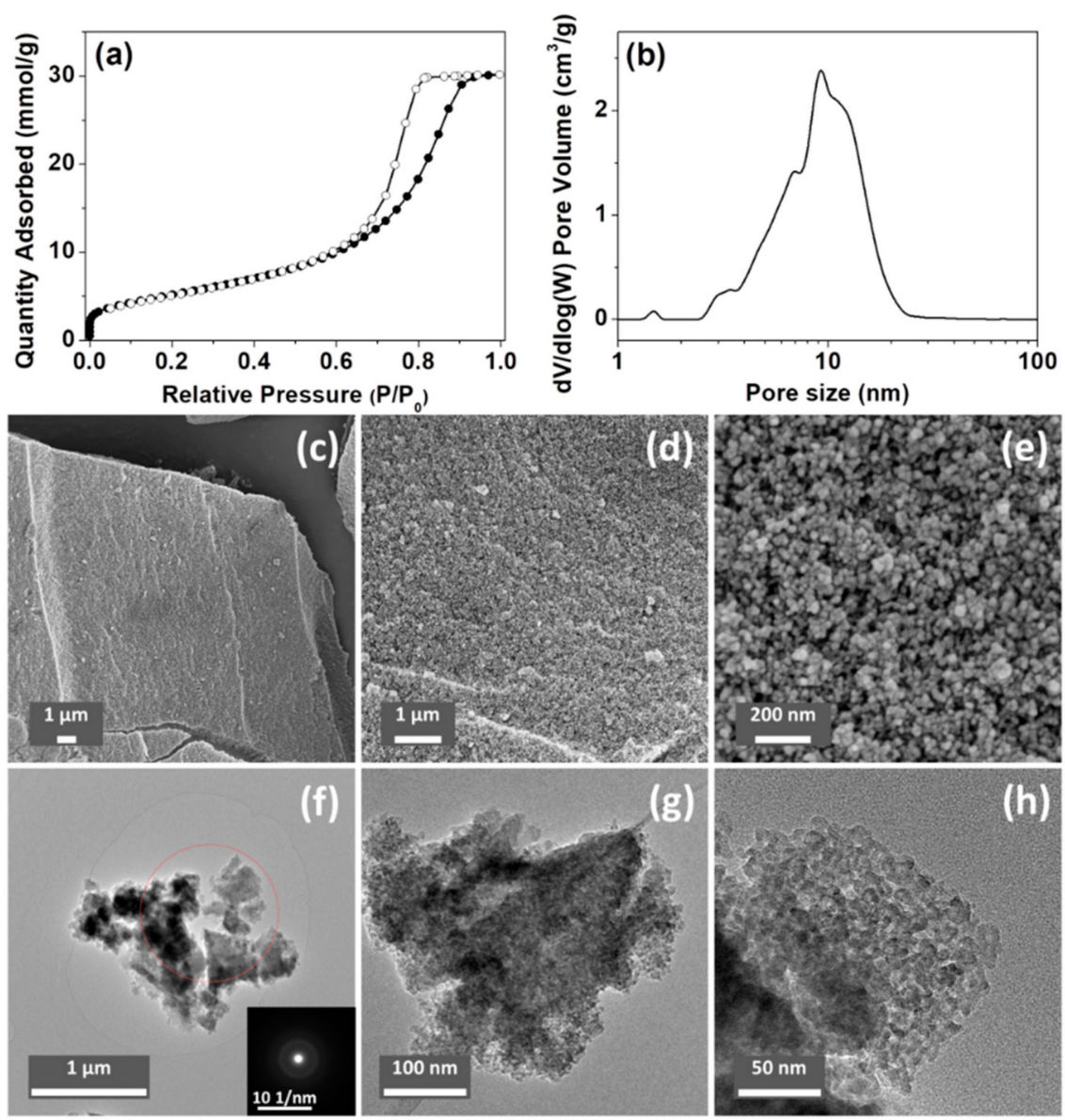

Figure 3. (a) $\mathrm{N}_{2}$ sorption isotherm and (b) density functional theory (DFT) pore-size distribution curve of ACP053. (c-e) scanning electron microscope (SEM) images and (f-h) transmission electron microscope (TEM) images of ACP053 (the insert in Figure $3 \mathrm{f}$ is the corresponding selected-area electron diffraction pattern). 
The SEM and TEM images of ACP053 are shown in Figure 3c-h. ACP053 had similar nanostructure as HPACC, which was constructed with aggregated nanoparticles. The ACP053 nanoparticles had no well-defined shape (e.g., exact spherical particles) or size according to the images shown in Figure 3c-h. From the high magnification images (Figure 3e,h), it can be seen that some of the ACP053 nanoparticles showed a certain level of coalescence. The nanoparticles on ACP053 appeared to be less uniformly shaped than those in HPACC. This was probably the reason behind the broader pore size distribution observed on ACP053 when compared with HPACC. These nanometer-sized ACP particles $(<10 \mathrm{~nm})$ appeared to have aggregated together without any particular order, similar to that observed in previous studies [28]. The porosity of ACP053 is the result of the space between these nanometer-size particles. The irregular porous structure of ACP053 was further confirmed by the STEM images shown in Figure S6. The average diameter of the individual particles was estimated, using the BET surface area and the density of ACP053 (2.59 g/ $\mathrm{cm}^{3}$, obtained by He pycnometry), to be $\sim 5.6 \mathrm{~nm}$ (modeled with non-porous spherical particles), which was in agreement with the TEM image shown in Figure $3 \mathrm{~h}$. The selected-area electron diffraction pattern in the insert of Figure $3 \mathrm{f}$ further confirmed the amorphous state of ACP053, even on a nanometer scale. The structure of the ACP032 particles was similar to those of ACP053 according to the SEM, TEM, and STEM images shown in Figures S7 and S8. In contrast, the crystalline CaP088 particles had plate-like structure with diameters of several micrometers, as shown in the SEM images in Figure S9.

In the rest of this study, we will focus only on the ACP032 and ACP053. These samples had high BET surface area that allow them to be utilized as potential functional materials for applications such as drug delivery and biomedicine.

LAXS was employed to determine the structure of ACP053. The LAXS radial distribution function (RDF) of ACP053 is shown in Figure 4 together with those of APC032 and HPACC [33]. The RDF for ACP published by Ranz et al. [49] (labeled as ACP-Ref in Figure 4) is included for comparison. The structures of the ACP053 and ACP032 samples were very similar to that of ACP-Ref, indicating that the calcium phosphate structure dominated during particle formation. The first peak in ACP-Ref at around $1.54 \AA$ corresponded to the $\mathrm{P}-\mathrm{O}$ distance in $\mathrm{PO}_{4}{ }^{3-}$ or $\mathrm{HPO}_{4}{ }^{2-}$ ions $[50,51]$. The first peak in the HPACC sample corresponded to the C-O distance at ca. $1.29 \AA$ [52]. For ACP053, the position of the first peak was identical to that reported for ACP-Ref, but, in ACP032, it was at a slightly shorter distance in accordance with the chemical composition of the sample. This suggested that ACP032 resembles both ACP-Ref and HPACC. The C-O peak in ACP032 was not clearly visible, which could be attributed to the low carbonate content in ACP032 ( 16 wt.\%) and less pronounced C-O peak when compared with the P-O peak. The peak at around 2.39 $\AA$ in the RDFs for ACP053 and ACP032 was associated with the $\mathrm{Ca}-\mathrm{O}$ distance in the 6-coordination, octahedral geometry of oxygens of $\mathrm{PO}_{4}{ }^{3-} \mathrm{Or} \mathrm{HPO}_{4}{ }^{2-}$ ions around the $\mathrm{Ca}^{2+}$ ions, similar to that observed for ACP-Ref. For HPACC, the corresponding peak was observed at a significantly longer distance (2.52 $\AA$ ). This is due to 8-coordinated $\mathrm{Ca}^{2+}$ in HPACC as discussed in our previous work [33]. The Ca-O distance in ACP053 and ACP032 appeared to be more similar to that in ACP-Ref than that in HPACC, which further corroborated that the ACP structure type dominated in ACP032 and ACP053 regardless of the amount of carbonate ions present. However, the shoulders in the RDF at about $4.05 \AA$, $6.80 \AA$ and $9.85 \AA$ (short dashed lines in Figure 4), which are fingerprinting features for ACP, appeared more pronounced in the RDF of ACP053. Both ACP053 and ACP032 showed distinct peaks up to $17.5 \AA$ suggesting that, although these two samples were amorphous, they had a detectable short-range atomic order. The short-range atomic order observed for ACP053 was much more pronounced than the reported short-range atomic order up to $9.5 \AA$ for ACP (of which the basic structural unit is the so-called Posner's cluster) with a formula of $\mathrm{Ca}_{9}\left(\mathrm{PO}_{4}\right)_{6}[24,25,50]$. The fact that the RDFs for ACP053, ACP032, and ACP-Ref were in principle superimposable implies that ACP053 and ACP032 had similar building blocks to ACP-Ref. 


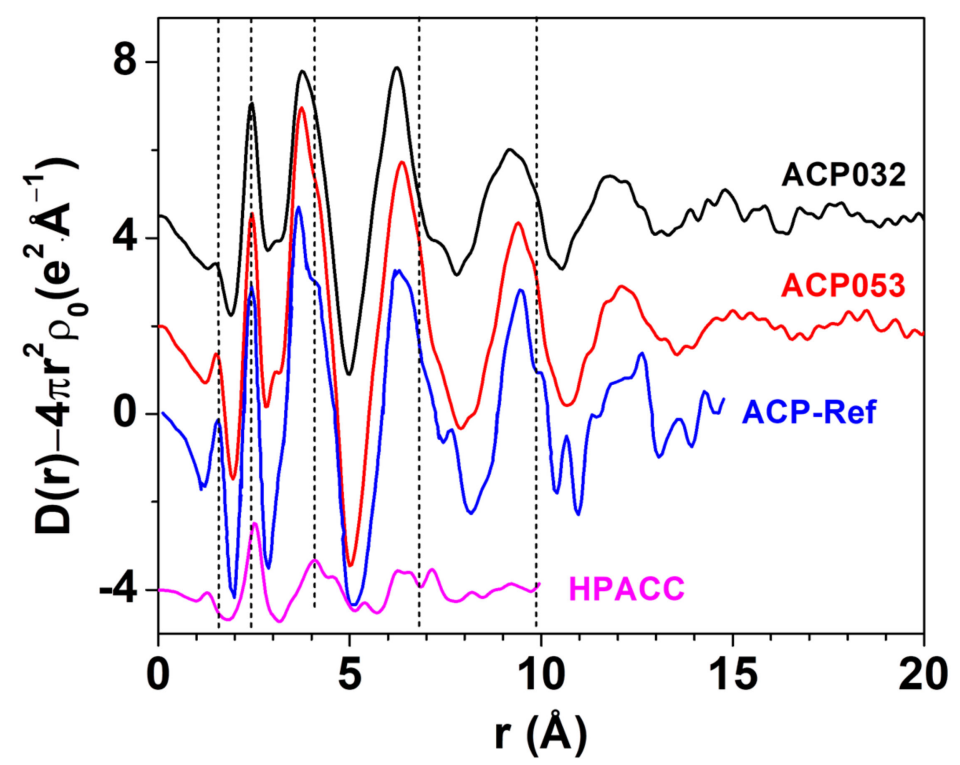

Figure 4. The large angle X-ray scattering (LAXS)-radial distribution function (RDF) of ACP053, ACP032, ACP-Ref and highly porous amorphous calcium carbonate (HPACC). The curves have been shifted vertically for better visibility. The ACP-Ref data were sourced and rescaled from Ref. [25], while the HPACC data were obtained by us and presented in a previous work Ref. [33].

\subsection{Stability of ACPs}

The stability of the synthesized ACPs was tested under different storage conditions. When stored in open air (relative humidity of approximately 43\%), ACP053 and ACP032 remained amorphous even after 14 months as confirmed by PXRD and IR (Figure S10). The storage stability observed here appeared to surpass that reported for other ACPs in the literature (Table S2). The excellent stability of the ACPs may have been attributed to the presence of $\mathrm{CO}_{3}{ }^{2-}$, as revealed by ICP-OES (Table S1), and the unique synthesis process (e.g., synthesized in methanol and dried at $150{ }^{\circ} \mathrm{C}$ ). The long-term storage stability in an amorphous state in air conditions exhibited by ACPs is a key advantage for their potential use in various applications. The decrease in the BET surface area of ACP053 was $~ 60 \%$ after 12 months (Figure S11). This decrease in BET surface area was probably related to intergrowth of the nanometer-sized particles. The increased pore size of ACP053 after storage for 12 months in open air also suggests that the drop in BET surface area was related to the growth of nanoparticles. The same observation has been noted for other similarly structured materials, such as mesoporous magnesium carbonate and HPACC $[33,53]$; their stability was increased by loading them with guest molecules such as additives or pharmaceuticals.

We have also studied the stability of ACP053 in de-ionized water. Crystallization of ACP in water is typically accompanied by an abrupt drop in $\mathrm{pH}[21,54]$. The $\mathrm{pH}$ change of a dispersion of $0.1 \mathrm{~g}$ of ACP053 in $10 \mathrm{~mL}$ de-ionized water at room temperature was followed in order to monitor the crystallization process; Figure 5a shows the $\mathrm{pH}$ of ACP053 dispersed in de-ionized water over time. The initial $\mathrm{pH}$ of the de-ionized water was $\sim 6.8$, rising to 7.7 in the first $30 \mathrm{~min}$ after adding $\mathrm{ACP} 053$. This rise in $\mathrm{pH}$ is presumably due to the high solubility of ACP053 and the small amount of carbonate present. The $\mathrm{pH}$ remained stable during the first $2 \mathrm{~h}$ followed by a gradual decrease over the next $3 \mathrm{~h}$. The $\mathrm{pH}$ was about 7.4 five hours after the addition of ACP053. During the following two $\mathrm{h}$, there was a significant drop in the $\mathrm{pH}$ of the dispersion (to 6.7). The PXRD patterns for ACP053 dispersed in de-ionized water over the same time frame are shown in Figure 5b. According to these PXRD patterns, ACP053 remained amorphous for up to $3 \mathrm{~h}$ in water. Thereafter, crystallization was noted by the appearance of a weak diffraction peak at $2 \theta=26^{\circ}$. The intensity of this peak increased further after $5 \mathrm{~h}$ of exposure to water. After $7 \mathrm{~h}$, ACP053 had been converted to HA (Figure S12a). The time-resolved PXRD patterns shown in Figure $7 \mathrm{~b}$ were in agreement with the results obtained in 
the $\mathrm{pH}$ study as described above. In summary, ACP053 was generally stable in water and remained amorphous for the first $2 \mathrm{~h}$. Thereafter, a phase transition from ACP053 to HA did take place with increasing rate with time, especially after five hours. These results are comparable with ion-doped ACPs reported in the literature [21]. After $7 \mathrm{~h}$ of exposure to water, the PXRD pattern (Figure 5b and Figure S12a) showed that HA had formed. The time-resolved IR spectra (Figure S12b) also confirmed that ACP053 was stable during the first $2 \mathrm{~h}$ but had fully crystallized after $7 \mathrm{~h}$. The broad $v_{3}$ vibration band of $\mathrm{PO}_{4}{ }^{3-}$ at $1050 \mathrm{~cm}^{-1}$ became a sharp band at $1025 \mathrm{~cm}^{-1}$ with a shoulder at around $1100 \mathrm{~cm}^{-3}$ and the $v_{4}$ band at around $560 \mathrm{~cm}^{-1}$ had split into two bands at 602 and $561 \mathrm{~cm}^{-1}$. These new vibration bands are characteristic for HA [40]. The SEM images of ACP053 after 15 h of exposure to water are shown in Figure S13. These images showed that the nanometer-sized particles observed in Figure 5 had aggregated and crystallized into crystals of around 100-200 nm in the longest dimension. The general morphology of the HA formed from ACP053 after exposure to water for $15 \mathrm{~h}$ was similar to that of carbonated HA crystals found in bones (with a length of about $100 \mathrm{~nm}$, width of 20-30 nm, and thickness of 3-6 nm) [55]. It has been documented that the nanometer-sized HA crystals exhibit biological properties such as non-toxicity, and higher bio-resorbability and osteoblast adhesion compared with crystalline CaP [10,56,57]. The formation of HA crystallized from ACP053 could, therefore, be a promising candidate for bone regeneration applications. ACP032 was also tested for its stability when exposed to de-ionized water. It had an extended lifetime $(>20 \mathrm{~h})$ in de-ionized water without any crystallization (see Supporting Information, Figures S14 and S15), surpassing the data reported for other ACPs [21,26,58]. The SEM images of ACP032 exposed to water for 50 days (Figure S16) showed relatively large calcite crystals and small HA crystals. This observation fitted well with the PXRD patterns (Figure S15) where strong diffraction peaks for calcite and weak diffraction peaks for HA were observed independently. These calcite and HA crystals formed separately from each other (i.e., no particle intergrowth), which is in agreement with the observation made by Kababya et al. on phosphate-doped ACC [59]. During the crystallization process, the formation of calcite was faster than that of HA and dominated in the overall transformation, as seen from the time-resolved IR spectra (Figure S14) and PXRD patterns (Figure S15). The stability study carried out here further confirmed that the carbonate content in ACP played a significant role in its stability and in the formation of HA from ACP [60]. A comparison of the stability of different ACPs in water is summarized in Table S3.
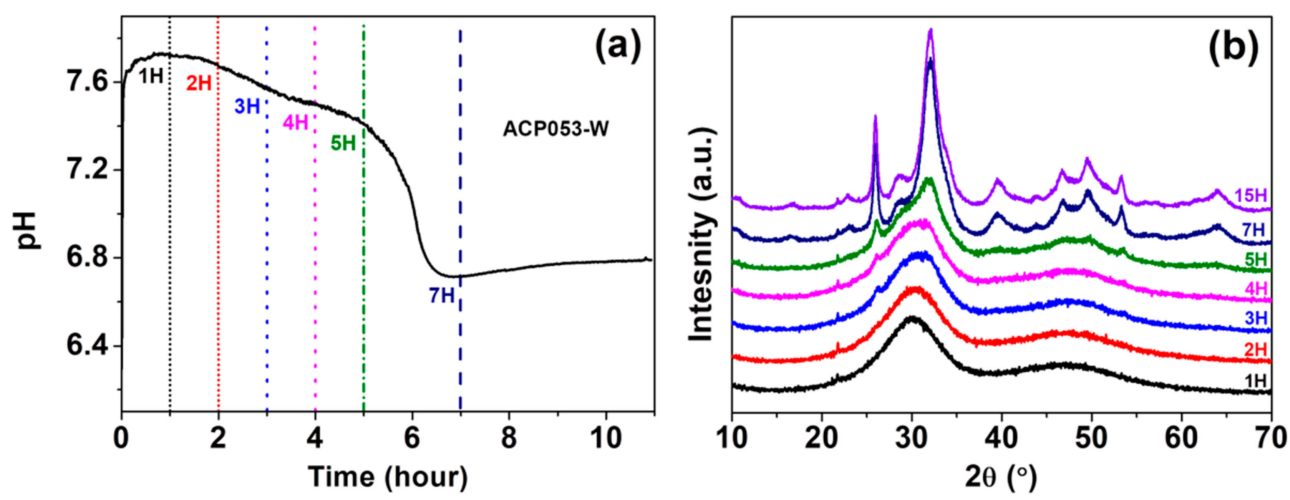

Figure 5. (a) $\mathrm{pH}$ changes over 1-7 $\mathrm{h}$ in a dispersion of ACP053 in de-ionized water and (b) powder $\mathrm{X}$-ray diffraction (PXRD) patterns for ACP053 exposed to de-ionized water for 1-15 $\mathrm{h}$.

\subsection{Cytocompatibility Study of ACPS}

The cytocompatibility of calcium carbonate and calcium phosphates with osteoblastic cells has been well documented over the years [1-3,61-65]. However, changes in the physico-chemical properties of the material, such as crystallinity, porosity, and particle size and morphology, can have notable effects on the response of exposed cells [66]. Therefore, mouse pre-osteoblastic cells (MC3T3) were chosen to conduct an in vitro cytotoxicity study as a first step in the biocompatibility evaluation of the newly synthesized ACPs, bearing in mind the potential use of the composites for bone regeneration 
and drug delivery applications. The metabolic activity of cells treated with ACP032 and ACP053 at concentrations from $25 \mu \mathrm{g} / \mathrm{mL}$ to $500 \mu \mathrm{g} / \mathrm{mL}$ for $24 \mathrm{~h}$ and $48 \mathrm{~h}$ did not significantly differ from that of untreated cells (the negative control) (Figure 6a,b). The percentage of cell viability respect to the negative control is above the $70 \%$ toxicity limit established by the International Organization for Standardization (ISO) standard (ISO 10993-5:2009) [67], for all sample concentrations and both exposure times.

(a)

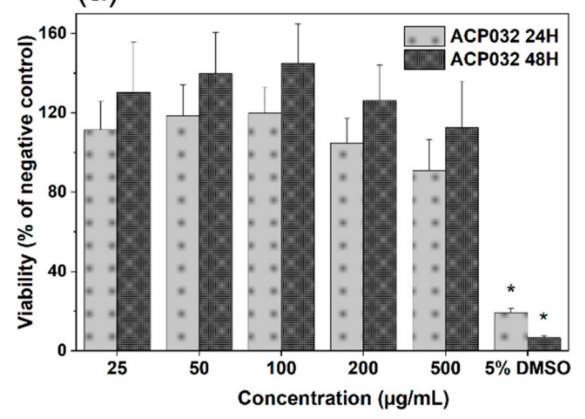

(c) (b)

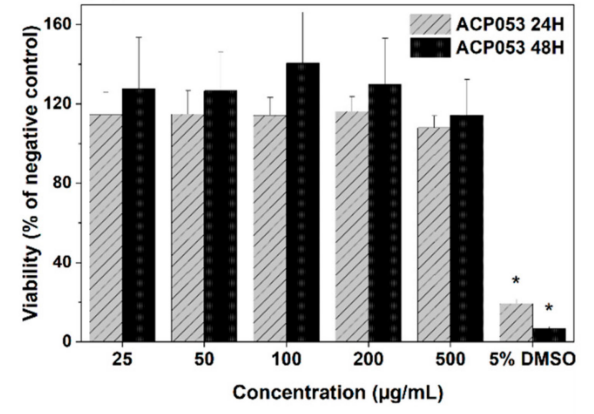

$48 H$

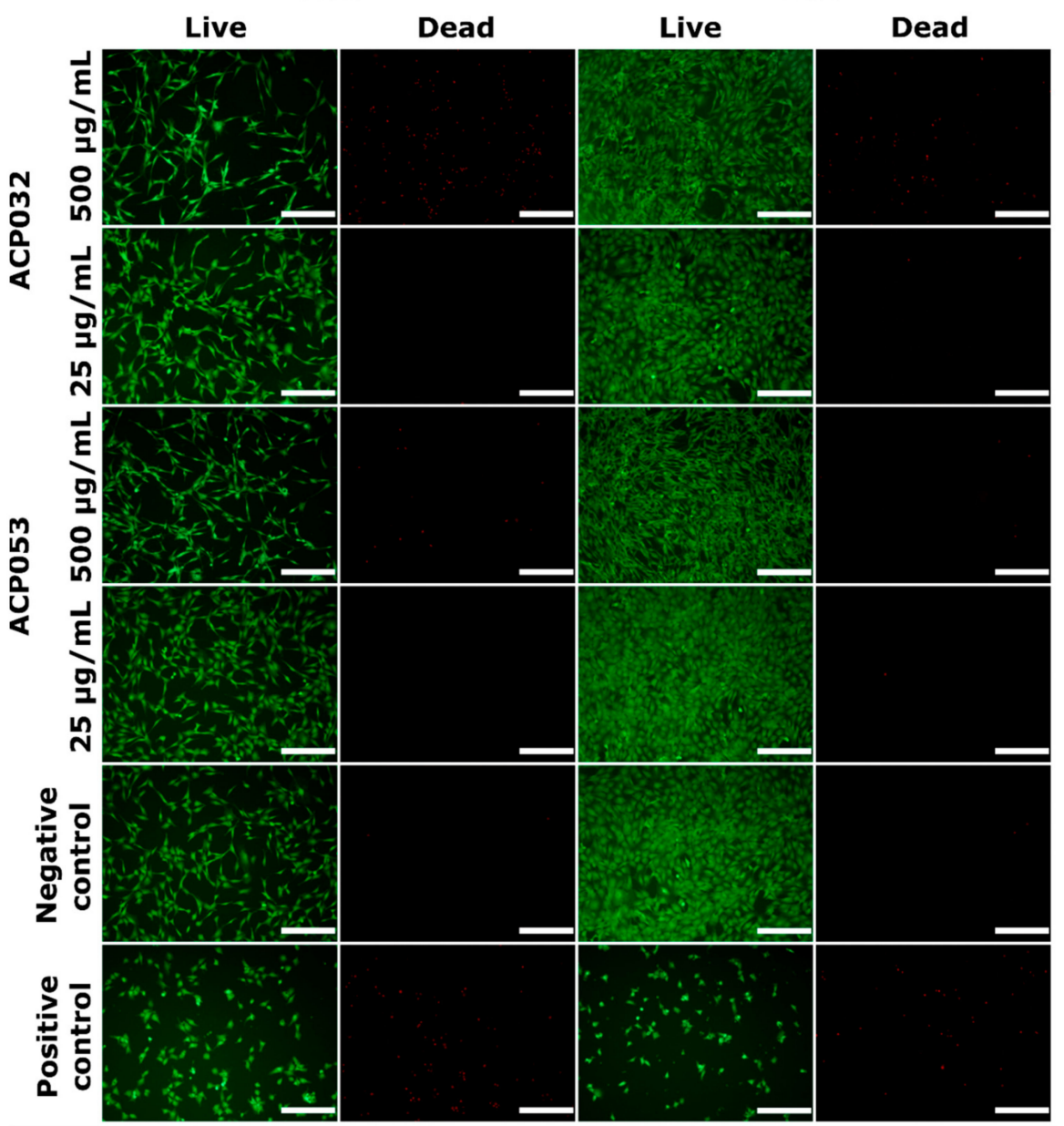

Figure 6. Cell viability of MC3T3 cells exposed to varying concentrations of (a) ACP032 and (b) ACP053 for $24 \mathrm{~h}$ and $48 \mathrm{~h}$. The data are presented as means \pm standard error of the mean for $n=6$, where significant differences $(p<0.05)$ compared to the negative control are marked with an asterisk $\left({ }^{*}\right)$; (c) live/dead staining of MC3T3 cells exposed to $500 \mu \mathrm{g} / \mathrm{mL}$ or $25 \mu \mathrm{g} / \mathrm{mL}$ of the amorphous calcium phosphate samples ACP032 and ACP053 for $24 \mathrm{~h}$ and $48 \mathrm{~h}$. The negative and positive controls were unexposed cells and cells treated with 5\% DMSO, respectively. The scale bar in Figure 6c is $100 \mu \mathrm{m}$. 
Live/dead staining of MC3T3 cells was employed to visually evaluate any changes in the cell morphology as well as an indicator of cell membrane integrity. Two concentrations of ACP032 and ACP053, $500 \mu \mathrm{g} / \mathrm{mL}$ and $25 \mu \mathrm{g} / \mathrm{mL}$ were used for the assay. As seen in Figure $6 \mathrm{c}$, the morphology and density of the viable cells after $24 \mathrm{~h}$ and $48 \mathrm{~h}$ of exposure at both high and low concentrations were comparable to those of the untreated cells (negative control). It should be noted that a relative high number of non-viable cells was observed after exposure to $500 \mu \mathrm{g} / \mathrm{mL}$ ACP032 (Figure 6c). However, the viable cell morphology remained fibroblast-like throughout the incubation period, in conjunction with a statistically significant $(p<0.05)$ cell proliferation after $48 \mathrm{~h}$. Overall, the results indicated a non-toxic effect of the ACP materials when MC3T3 cells were exposed to the materials under the conditions of the study.

The stability of the ACPs when exposed to cell culture medium was also investigated by monitoring the PXRD pattern and IR spectra for ACP in the cell culture medium over time. Both ACP053 and ACP032 demonstrated higher stability in the cell culture medium than in de-ionized water (Figures S17 and S18). ACP053 started to crystallize to HA after $24 \mathrm{~h}$, while ACP032 remained amorphous for up to $48 \mathrm{~h}$. The enhanced stability in cell culture medium compared with that in de-ionized water could be related to the proteins present in the cell culture medium which may act as a stabilizer for ACPs [68]. In addition, the crystallization of ACP053 to HA over the time period of cell exposure did not seem to significantly affect the observed cell response.

\subsection{Drug Loading and In Vitro Release of AL with ACP053 as Carrier}

ACP053 was selected for further studies as a possible carrier for anti-osteoporosis bisphosphonate (BP) drugs. AL was chosen as the model drug to load into ACP053 by a soaking method as described in the experimental section. The loading percentage of AL was determined to be $\sim 5.6 \mathrm{wt} . \%$ and loading efficiency was $\sim 87.88 \%$, which is comparable to the value reported in literature [69]. The ACP053 loaded with AL (ACP053-AL) remained amorphous, as seen in the PXRD pattern (Figure S19). ACP053-AL had a BET surface area of $\sim 370 \mathrm{~m}^{2} / \mathrm{g}$ and a pore volume of $1.11 \mathrm{~cm}^{3} / \mathrm{g}\left(\mathrm{N}_{2}\right.$ sorption isotherms in Figure S20). The high porosity of ACP053-AL implied that AL was loaded into the pores of ACP053. The pore volume of ACP053-AL was $1.11 \mathrm{~cm}^{3} / \mathrm{g}$, comparable to the expected value calculated based on full AL adsorption on the pore surface (i.e., not on the surface of the ACP053 particles) of $1.07 \mathrm{~cm}^{3} / \mathrm{g}$. The high pore volume on ACP053-AL was a clear indication that AL was not adsorbed on the surface of ACP053 and not blocking the pore opening of ACP053.

The in vitro release of AL was assessed in an HEPES buffer saline (10 mM, $\mathrm{pH}=7.0-7.6)$. The AL release curve is shown in Figure 7. Up to $\sim 25 \%$ of the total amount of loaded AL was released in 22 days. After 22 days, the release of AL appeared to fluctuate at around the same level and no further significant release of AL was noted up to 40 days. The slow release rate and limited release percentage of AL are comparable to those of other materials tested for loading and release of AL [70,71] as well as other BPs $[55,72,73]$. Our group previously reported loading of the BP pamidronate within biomimetic HA with a non-measurable release [74]. Palazzo et al. reported the loading and release of $\mathrm{AL}$ with biomimetic HA as the carrier; the release percentage was $\sim 20 \%$ after one day with a slight increase to $\sim 25 \%$ after 18 days [55]. Kim et al. loaded AL into CaP microspheres in situ, with a loading percentage of $14.4 \mathrm{wt} . \%$ [73]. The AL-loaded CaP released $\sim 18 \%$ of the AL after 20 days followed by continuous release of up to $\sim 24 \%$ after 40 days. The slow release rate and limited release percentage may be related to the strong interaction between AL and ACP053. It has been documented that there are significant differences in the affinity constants for HA among the BPs, with a rank order of zoledronate $>$ alendronate $>$ ibandronate $>$ risedronate $>$ etidronate $>$ clodronate [75]. Palazzo et al. proposed that the adsorption of negatively charged AL is favored on the calcium-rich HA surface [55]. As for ACP053, the high specific surface area and the presence of a small amount of carbonate $(\sim 4$ wt.\%) could enhance the adsorption/loading of AL into ACP053. This could result in the slow release rate in vitro as observed. On the other hand, the limited release percentage of AL demonstrated by ACP053 may not necessarily be a drawback for some applications. The incomplete release of AL from 
ACP053 could be beneficial for the formation of dense bone structures in, for example, bone healing application. The dissolution of ACP053 is retarded by the presence of AL and the AL could also inhibit the formation of osteoclast. The lack of osteoclast would allow the osteoblasts to form a dense bone structure [74].

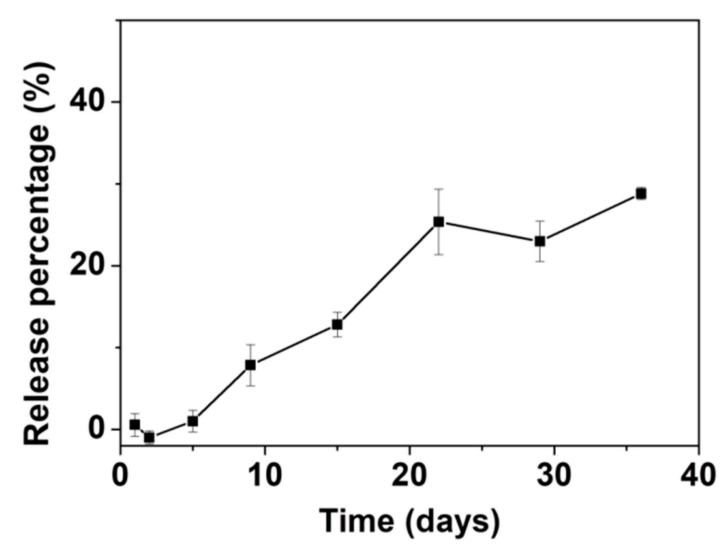

Figure 7. Graph showing the release of alendronate (AL) from ACP053-AL in N-(2-Hydroxyethyl)pip erazine- $\mathrm{N}^{\prime}$-(2-ethanesulfonic acid) (HEPES) buffer $(10 \mathrm{mM}, \mathrm{pH}=7.0-7.6)$. All measurements were performed in triplicate and the mean concentrations and corresponding deviations were calculated.

\section{Conclusions}

A series of ACPs and crystalline CaPs were successfully synthesized by introducing phosphoric acid into an ACC suspension in methanol at room temperature. ACPs with varying levels of carbonate content (from 4-16 wt.\%) showed increased BET surface areas (over $400 \mathrm{~m}^{2} / \mathrm{g}$ ) over other ACPs previously reported in literature. The synthesized ACPs were composed of small ACP nanoparticles of several nanometers in size. These ACP nanoparticles had a short-range atomic order up to $20 \AA$ and were stable and remained amorphous for more than one year in air. When exposed to de-ionized water, the ACPs remained amorphous for a number of hours, depending on the carbonate content, but converted to HA with time. The ACPs were cytocompatible with bone cells in vitro and ACP053 had the ability to carry and release bisphosphate (e.g., AL). As ACP is a precursor for the formation of the important biomaterial HA, the ability to obtain ACP with high porosity and long-term storage stability is promising for the development of ACP for certain bio-medical applications, such as bone therapy and drug delivery. For example, the HA formed from ACP053 exposed in de-ionized water exhibited similar microstructure as carbonated HA crystals found in bones, which indicated the potential applications of this HA in bone healing. This ACP material could be used a gradient for calcium phosphate-based cement as its high bioactive. The high porosity would facilitate the high loading content and $\mathrm{pH}$ sensitive property of ACP could also endow the $\mathrm{pH}$ sensitive release of drugs. The performance of these high surface area and stable ACPs in these potential applications should be further explored.

Supplementary Materials: The following are available online at http://www.mdpi.com/2079-4991/10/1/20/s1, Figure S1: PXRD pattern for CaP088; Figure S2: TGA and DSC curves for CaP068, CaP078 and CaP088; Figure S3: TGA curve of ACP032; Figure S4: High-resolution X-ray photoelectron spectroscopy of ACP053 and ACP032; Figure S5: $\mathrm{N}_{2}$ adsorption-desorption isotherms and density functional theory pore-size distribution curves; Table S1: Comparison of the synthesis methods, particle sizes, BET surface areas, pore volumes, pore sizes and applications of ACP samples synthesized in this work and other ACP and crystalline CaP samples reported in the literature; Figure S6: STEM images of ACP053; Figure S7: SEM and TEM images of ACP032; Figure S8: STEM images of ACP032; Figure S9: SEM images of CaP088; Figure S10: PXRD patterns and IR spectra ACP053 and ACP032 after storage under ambient conditions for 14 months; Table S2: Comparison of the stability of ACP samples synthesized in this work or reported in the literature; Figure S11: $\mathrm{N}_{2}$ adsorption/desorption isotherms and density functional theory pore-size distribution curves for ACP053 as synthesized and after storage under ambient conditions for 12 months; Figure S12: PXRD pattern for ACP053 after exposure to de-ionized water for $15 \mathrm{~h}$ and IR spectra for ACP053 after immersion in de-ionized water for 1-15 h; Figure S13: SEM images of the hydroxyapatite formed from ACP053 after exposure to de-ionized water for 15 h; Figure S14: IR spectra for ACP032 after exposure 
to de-ionized water for $1 \mathrm{~h}$ to 50 days and IR spectra for ACP032 after exposure to de-ionized water for 1 hour and 30 days; Figure S15: PXRD patterns for ACP032 after exposure to de-ionized water for $1 \mathrm{~h}$ to 50 days and 30 days; Figure S16: SEM images of ACP032 after exposure to de-ionized water for 50 days; Figure S17: PXRD patterns IR spectra for ACP053 after exposure to cell culture medium for 5-48 h; Figure S18: PXRD pattern and IR spectra for ACP032 after exposure to cell culture medium for 5-48 h; Figure S19: PXRD patterns for ACP053 before and after loading with alendronate; Figure S20: $\mathrm{N}_{2}$ sorption isotherms for ACP053 before and after loading with alendronate and the corresponding density functional theory pore-size distribution graphs.

Author Contributions: Material synthesis: R.S. and F.d.K.; acquisition of data: R.S., F.d.K., M.Å., C.-W.T., É.G.B., I.P., and O.C.; interpretation of data: R.S., M.Å., C.-W.T., É.G.B., N.F., I.P., and O.C.; drafting the manuscript: R.S., M.Å., C.-W.T., É.G.B., N.F., I.P., M.S., and O.C.; revising the manuscript: R.S., M.Å., F.d.K., É.G.B., C.-W.T., N.F., I.P., M.S., and O.C. All authors have read and agreed to the published version of the manuscript.

Funding: The Swedish Research Council (Grant No. 2014-3929), the Swedish Research Council for Sustainable Development (FORMAS, Grant No. 2018-00651) and the Åforsk Foundation (Grant No. 19-549) are gratefully acknowledged for funding this work. Rui Sun thanks the China Scholarship Council (CSC) for financial support. The Kunt and Alice Wallenberg Foundation is acknowledged for financing the electron microscopy facility at Stockholm University.

Conflicts of Interest: The authors declare no conflict of interest.

\section{References}

1. Dorozhkin, S.V. Nanosized and nanocrystalline calcium orthophosphates. Acta Biomater. 2010, 6, 715-734. [CrossRef] [PubMed]

2. Kumta, P.N.; Sfeir, C.; Lee, D.-H.; Olton, D.; Choi, D. Nanostructured calcium phosphates for biomedical applications: Novel synthesis and characterization. Acta Biomater. 2005, 1, 65-83. [CrossRef] [PubMed]

3. Sun, F.; Zhou, H.; Lee, J. Various preparation methods of highly porous hydroxyapatite/polymer nanoscale biocomposites for bone regeneration. Acta Biomater. 2011, 7, 3813-3828. [CrossRef] [PubMed]

4. Mahamid, J.; Sharir, A.; Addadi, L.; Weiner, S. Amorphous calcium phosphate is a major component of the forming fin bones of zebrafish: Indications for an amorphous precursor phase. Proc. Natl. Acad. Sci. USA 2008, 105, 12748-12753. [CrossRef]

5. Lotsari, A.; Rajasekharan, A.K.; Halvarsson, M.; Andersson, M. Transformation of amorphous calcium phosphate to bone-like apatite. Nat. Commun. 2018, 9, 4170. [CrossRef]

6. Akiva, A.; Kerschnitzki, M.; Pinkas, I.; Wagermaier, W.; Yaniv, K.; Fratzl, P.; Addadi, L.; Weiner, S. Mineral formation in the larval zebrafish tail bone occurs via an acidic disordered calcium phosphate phase. J. Am. Chem. Soc. 2016, 138, 14481-14487. [CrossRef]

7. Chen, F.; Huang, P.; Qi, C.; Lu, B.-Q.; Zhao, X.-Y.; Li, C.; Wu, J.; Cui, D.-X.; Zhu, Y.-J. Multifunctional biodegradable mesoporous microspheres of $\mathrm{Eu}^{3+}$-doped amorphous calcium phosphate: Microwave-assisted preparation, pH-sensitive drug release, and bioimaging application. J. Mater. Chem. B 2014, 2, 7132-7140. [CrossRef]

8. Qi, C.; Zhu, Y.-J.; Zhang, Y.-G.; Jiang, Y.-Y.; Wu, J.; Chen, F. Vesicle-like nanospheres of amorphous calcium phosphate: Sonochemical synthesis using the adenosine $5^{\prime}$-triphosphate disodium salt and their application in pH-responsive drug delivery. J. Mater. Chem. B 2015, 3, 7347-7354. [CrossRef]

9. Yu, W.; Sun, T.-W.; Qi, C.; Ding, Z.; Zhao, H.; Chen, F.; Chen, D.; Zhu, Y.-J.; Shi, Z.; He, Y. Strontium-doped amorphous calcium phosphate porous microspheres synthesized through a microwave-hydrothermal method using fructose 1, 6-bisphosphate as an organic phosphorus source: Application in drug delivery and enhanced bone regeneration. ACS Appl. Mater. Interfaces 2017, 9, 3306-3317. [CrossRef]

10. Balasundaram, G.; Sato, M.; Webster, T.J. Using hydroxyapatite nanoparticles and decreased crystallinity to promote osteoblast adhesion similar to functionalizing with RGD. Biomaterials 2006, 27, 2798-2805. [CrossRef]

11. Nagano, M.; Nakamura, T.; Kokubo, T.; Tanahashi, M.; Ogawa, M. Differences of bone bonding ability and degradation behaviour in vivo between amorphous calcium phosphate and highly crystalline. Biomaterials 1996, 17, 1771-1777. [CrossRef]

12. Yao, S.; Xu, Y.; Zhou, Y.; Shao, C.; Liu, Z.; Jin, B.; Zhao, R.; Cao, H.; Pan, H.; Tang, R. Calcium phosphate nanocluster-loaded injectable hydrogel for bone regeneration. ACS Appl. Bio Mater. 2019, 2, 4408-4417. [CrossRef] 
13. Tovani, C.B.; Gloter, A.; Azaïs, T.; Selmane, M.; Ramos, A.P.; Nassif, N. Formation of stable strontium-rich amorphous calcium phosphate: Possible effects on bone mineral. Acta Biomater. 2019, 92, 315-324. [CrossRef] [PubMed]

14. Iafisco, M.; Degli Esposti, L.; Ramírez-Rodríguez, G.B.; Carella, F.; Gómez-Morales, J.; Ionescu, A.C.; Brambilla, E.; Tampieri, A.; Delgado-López, J.M. Fluoride-doped amorphous calcium phosphate nanoparticles as a promising biomimetic material for dental remineralization. Sci. Rep. 2018, 8, 17016. [CrossRef] [PubMed]

15. Van den Vreken, N.M.; Pieters, I.Y.; Declercq, H.A.; Cornelissen, M.J.; Verbeeck, R.M. Characterization of calcium phosphate cements modified by addition of amorphous calcium phosphate. Acta Biomater. 2010, 6, 617-625. [CrossRef] [PubMed]

16. Zhao, J.; Liu, Y.; Sun, W.-B.; Zhang, H. Amorphous calcium phosphate and its application in dentistry. Chem. Cent. J. 2011, 5, 40. [CrossRef] [PubMed]

17. Ortali, C.; Julien, I.; Vandenhende, M.; Drouet, C.; Champion, E. Consolidation of bone-like apatite bioceramics by spark plasma sintering of amorphous carbonated calcium phosphate at very low temperature. J. Eur. Ceram. Soc. 2018, 38, 2098-2109. [CrossRef]

18. Armstrong, W.; Singer, L. Composition and constitution of the mineral phase of bone. Clin. Orthop. Relat. Res. 1965, 38, 179-192. [CrossRef]

19. Olszta, M.J.; Cheng, X.; Jee, S.S.; Kumar, R.; Kim, Y.-Y.; Kaufman, M.J.; Douglas, E.P.; Gower, L.B. Bone structure and formation: A new perspective. Mater. Sci. Eng. Rep. 2007, 58, 77-116. [CrossRef]

20. Boanini, E.; Gazzano, M.; Bigi, A. Ionic substitutions in calcium phosphates synthesized at low temperature. Acta Biomater. 2010, 6, 1882-1894. [CrossRef]

21. Jin, W.; Liu, Z.; Wu, Y.; Jin, B.; Shao, C.; Xu, X.; Tang, R.; Pan, H. Synergic Effect of $\mathrm{Sr}^{2+}$ and $\mathrm{Mg}^{2+}$ on the Stabilization of Amorphous Calcium Phosphate. Cryst. Growth Des. 2018, 18, 6054-6060. [CrossRef]

22. Tadic, D.; Peters, F.; Epple, M. Continuous synthesis of amorphous carbonated apatites. Biomaterials 2002, 23, 2553-2559. [CrossRef]

23. Nakamura, M.; Hiratai, R.; Hentunen, T.; Salonen, J.; Yamashita, K. Hydroxyapatite with high carbonate substitutions promotes osteoclast resorption through osteocyte-like cells. ACS Biomater. Sci. Eng. 2016, 2, 259-267. [CrossRef]

24. Dorozhkin, S.V. Amorphous calcium (ortho) phosphates. Acta Biomater. 2010, 6, 4457-4475. [CrossRef] [PubMed]

25. Combes, C.; Rey, C. Amorphous calcium phosphates: Synthesis, properties and uses in biomaterials. Acta Biomater. 2010, 6, 3362-3378. [CrossRef] [PubMed]

26. Ibsen, C.J.S.; Leemreize, H.; Mikladal, B.F.; Skovgaard, J.; Bremholm, M.; Eltzholtz, J.R.; Iversen, B.B.; Birkedal, H. Alkali counter ions impact crystallization kinetics of apatite nanocrystals from amorphous calcium phosphate in water at high pH. Cryst. Growth Des. 2018, 18, 6723-6728. [CrossRef]

27. Meić, I.B.; Kontrec, J.; Jurašin, D.D.; Selmani, A.; Džakula, B.N.; Maltar-Strmečki, N.; Lyons, D.M.; Plodinec, M.; Čeh, M.; Gajović, A. How similar are amorphous calcium carbonate and calcium phosphate? A comparative study of amorphous phase formation conditions. CrystEngComm 2018, 20, 35-50. [CrossRef]

28. Layrolle, P.; Lebugle, A. Characterization and reactivity of nanosized calcium phosphates prepared in anhydrous ethanol. Chem. Mater. 1994, 6, 1996-2004. [CrossRef]

29. Ching Lau, C.; Reardon, P.J.T.; Campbell Knowles, J.; Tang, J. Phase-tunable calcium phosphate biomaterials synthesis and application in protein delivery. ACS Biomater. Sci. Eng. 2015, 1, 947-954. [CrossRef]

30. Mohsen-Nia, M.; Amiri, H.; Jazi, B. Dielectric constants of water, methanol, ethanol, butanol and acetone: Measurement and computational study. J. Solut. Chem. 2010, 39, 701-708. [CrossRef]

31. Rodrigues, A.; Lebugle, A. Influence of ethanol in the precipitation medium on the composition, structure and reactivity of tricalcium phosphate. Colloids Surf. A Physicochem. Eng. Asp. 1998, 145, 191-204. [CrossRef]

32. Li, Y.; Weng, W.; Cheng, K.; Du, P.; Shen, G.; Wang, J.; Han, G. Preparation of amorphous calcium phosphate in the presence of poly (ethylene glycol). J. Mater. Sci. Lett. 2003, 22, 1015-1016. [CrossRef]

33. Sun, R.; Zhang, P.; Bajnóczi, É.G.; Neagu, A.; Tai, C.-W.; Persson, I.; Strømme, M.; Cheung, O. Amorphous Calcium Carbonate Constructed from Nanoparticle Aggregates with Unprecedented Surface Area and Mesoporosity. ACS Appl. Mater. Interfaces 2018, 10, 21556-21564. [CrossRef] [PubMed] 
34. Powell, K.J.; Brown, P.L.; Byrne, R.H.; Gajda, T.; Hefter, G.; Sjöberg, S.; Wanner, H. Chemical speciation of environmentally significant heavy metals with inorganic ligands. Part 1: The $\mathrm{Hg}^{2+}-\mathrm{Cl}^{-}, \mathrm{OH}^{-}, \mathrm{CO}_{3}{ }^{2-}, \mathrm{SO}_{4}{ }^{2-}$, and $\mathrm{PO}_{4}{ }^{3-}$ aqueous systems (IUPAC Technical Report). Pure Appl. Chem. 2005, 77, 739-800. [CrossRef]

35. Greenwood, N.N.; Earnshaw, A. Chemistry of the Elements; Elsevier: Amsterdam, The Netherlands, 2012.

36. De Aza, P.; Santos, C.; Pazo, A.; De Aza, S.; Cusco, R.; Artus, L. Vibrational properties of calcium phosphate compounds. 1. Raman spectrum of $\beta$-tricalcium phosphate. Chem. Mater. 1997, 9, 912-915. [CrossRef]

37. Chatzipanagis, K.; Iafisco, M.; Roncal-Herrero, T.; Bilton, M.; Tampieri, A.; Kröger, R.; Delgado-López, J.M. Crystallization of citrate-stabilized amorphous calcium phosphate to nanocrystalline apatite: A surface-mediated transformation. CrystEngComm 2016, 18, 3170-3173. [CrossRef]

38. Casciani, F.; Condrate, R., Sr. The Raman spectrum of monetite, $\mathrm{CaHPO}_{4}$. J. Solid State Chem. 1980, 34, 385-388. [CrossRef]

39. Zyman, Z.; Epple, M.; Goncharenko, A.; Rokhmistrov, D.; Prymak, O.; Loza, K. Thermally induced crystallization and phase evolution in powders derived from amorphous calcium phosphate precipitates with a Ca/P ratio of 1:1. J. Cryst. Growth 2016, 450, 190-196. [CrossRef]

40. Berzina-Cimdina, L.; Borodajenko, N. Research of calcium phosphates using Fourier transform infrared spectroscopy. In Infrared Spectroscopy-Materials Science, Engineering and Technology; IntechOpen: London, UK, 2012.

41. Layrolle, P.; Lebugle, A. Synthesis in pure ethanol and characterization of nanosized calcium phosphate fluoroapatite. Chem. Mater. 1996, 8, 134-144. [CrossRef]

42. Brangule, A.; Gross, K.A. Importance of FTIR Spectra Deconvolution for the Analysis of Amorphous Calcium Phosphates. In Proceedings of the IOP Conference Series: Materials Science and Engineering, Riga, Latvia, 29 September-2 October 2014; p. 012027.

43. Yang, L.; Perez-Amodio, S.; Barrère-de Groot, F.Y.; Everts, V.; van Blitterswijk, C.A.; Habibovic, P. The effects of inorganic additives to calcium phosphate on in vitro behavior of osteoblasts and osteoclasts. Biomaterials 2010, 31, 2976-2989. [CrossRef]

44. Singh, S.S.; Roy, A.; Lee, B.E.; Banerjee, I.; Kumta, P.N. MC3T3-E1 proliferation and differentiation on biphasic mixtures of $\mathrm{Mg}$ substituted $\beta$-tricalcium phosphate and amorphous calcium phosphate. Mater. Sci. Eng. C 2014, 45, 589-598. [CrossRef] [PubMed]

45. Uskoković, V.; Marković, S.; Veselinović, L.; Škapin, S.; Ignjatović, N.; Uskoković, D.P. Insights into the kinetics of thermally induced crystallization of amorphous calcium phosphate. PCCP 2018, 20, 29221-29235. [CrossRef] [PubMed]

46. Ding, G.-J.; Zhu, Y.-J.; Qi, C.; Lu, B.-Q.; Chen, F.; Wu, J. Porous hollow microspheres of amorphous calcium phosphate: Soybean lecithin templated microwave-assisted hydrothermal synthesis and application in drug delivery. J. Mater. Chem. B 2015, 3, 1823-1830. [CrossRef]

47. Hwang, E.T.; Tatavarty, R.; Chung, J.; Gu, M.B. New functional amorphous calcium phosphate nanocomposites by enzyme-assisted biomineralization. ACS Appl. Mater. Interfaces 2013, 5, 532-537. [CrossRef] [PubMed]

48. Zhao, X.Y.; Zhu, Y.J.; Qi, C.; Chen, F.; Lu, B.Q.; Zhao, J.; Wu, J. Hierarchical Hollow Hydroxyapatite Microspheres: Microwave-Assisted Rapid Synthesis by Using Pyridoxal-5'-Phosphate as a Phosphorus Source and Application in Drug Delivery. Chem. Asian J. 2013, 8, 1313-1320. [CrossRef] [PubMed]

49. Ranz, X. Développement et Caractérisation de Dépôts D'apatite Obtenus par Projection Plasma sur Prothèses Orthopédiques; INPT: Toulouse, France, 1996.

50. Betts, F.; Posner, A. An X-ray radial distribution study of amorphous calcium phosphate. Mater. Res. Bull. 1974, 9, 353-360. [CrossRef]

51. Persson, I.; Trublet, M.; Klysubun, W. Structure Determination of Phosphoric Acid and Phosphate Ions in Aqueous Solution Using EXAFS Spectroscopy and Large Angle X-ray Scattering. J. Phys. Chem. A 2018, 122, 7413-7420. [CrossRef] [PubMed]

52. Demichelis, R.; Raiteri, P.; Gale, J.D.; Dovesi, R. A new structural model for disorder in vaterite from first-principles calculations. CrystEngComm 2012, 14, 44-47. [CrossRef]

53. Cheung, O.; Zhang, P.; Frykstrand, S.; Zheng, H.; Yang, T.; Sommariva, M.; Zou, X.; Strømme, M. Nanostructure and pore size control of template-free synthesised mesoporous magnesium carbonate. RSC Adv. 2016, 6, 74241-74249. [CrossRef] 
54. Christoffersen, J.; Christoffersen, M.R.; Kibalczyc, W.; Andersen, F.A. A contribution to the understanding of the formation of calcium phosphates. J. Cryst. Growth 1989, 94, 767-777. [CrossRef]

55. Palazzo, B.; Iafisco, M.; Laforgia, M.; Margiotta, N.; Natile, G.; Bianchi, C.L.; Walsh, D.; Mann, S.; Roveri, N. Biomimetic hydroxyapatite-drug nanocrystals as potential bone substitutes with antitumor drug delivery properties. Adv. Funct. Mater. 2007, 17, 2180-2188. [CrossRef]

56. Murugan, R.; Ramakrishna, S. Aqueous mediated synthesis of bioresorbable nanocrystalline hydroxyapatite. J. Cryst. Growth 2005, 274, 209-213. [CrossRef]

57. Murugan, R.; Ramakrishna, S. Bioresorbable composite bone paste using polysaccharide based nano hydroxyapatite. Biomaterials 2004, 25, 3829-3835. [CrossRef] [PubMed]

58. Shahrezaee, M.; Raz, M.; Shishehbor, S.; Moztarzadeh, F.; Baghbani, F.; Sadeghi, A.; Bajelani, K.; Tondnevis, F. Synthesis of Magnesium Doped Amorphous Calcium Phosphate as a Bioceramic for Biomedical Application: In Vitro Study. Silicon 2018, 10, 1171-1179. [CrossRef]

59. Kababya, S.; Gal, A.; Kahil,K.; Weiner, S.; Addadi, L.; Schmidt, A. Phosphate-water interplay tunes amorphous calcium carbonate metastability: Spontaneous phase separation and crystallization vs stabilization viewed by solid state NMR. J. Am. Chem. Soc. 2015, 137, 990-998. [CrossRef]

60. Blumenthal, N.; Betts, F.; Posner, A. Effect of carbonate and biological macromolecules on formation and properties of hydroxyapatite. Calcif. Tissue Res. 1975, 18, 81-90. [CrossRef]

61. Sharma, S.; Verma, A.; Teja, B.V.; Pandey, G.; Mittapelly, N.; Trivedi, R.; Mishra, P. An insight into functionalized calcium based inorganic nanomaterials in biomedicine: Trends and transitions. Colloids Surf. B Biointerfaces 2015, 133, 120-139. [CrossRef]

62. Dizaj, S.M.; Barzegar-Jalali, M.; Zarrintan, M.H.; Adibkia, K.; Lotfipour, F. Calcium carbonate nanoparticles; potential in bone and tooth disorders. Pharm. Sci. 2015, 20, 175-182.

63. Combes, C.; Bareille, R.; Rey, C. Calcium carbonate-calcium phosphate mixed cement compositions for bone reconstruction. J. Biomed. Mater. Res. Part A 2006, 79, 318-328. [CrossRef]

64. Tolba, E.; Müller, W.E.; El-Hady, B.M.A.; Neufurth, M.; Wurm, F.; Wang, S.; Schröder, H.C.; Wang, X. High biocompatibility and improved osteogenic potential of amorphous calcium carbonate/vaterite. J. Mater. Chem. B 2016, 4, 376-386. [CrossRef]

65. Combes, C.; Miao, B.; Bareille, R.; Rey, C. Preparation, physical-chemical characterisation and cytocompatibility of calcium carbonate cements. Biomaterials 2006, 27, 1945-1954. [CrossRef] [PubMed]

66. Uskoković, V.; Batarni, S.S.; Schweicher, J.; King, A.; Desai, T.A. Effect of calcium phosphate particle shape and size on their antibacterial and osteogenic activity in the delivery of antibiotics in vitro. ACS Appl. Mater. Interfaces 2013, 5, 2422-2431. [CrossRef] [PubMed]

67. Biological Evaluation of Medical Devices_Part 5: Tests for In Vitro Cytotoxicity. 2009. Available online: https://www.iso.org/obp/ui/\#iso:std:iso:10993:-10995:ed-10993:v10991:en (accessed on 1 September 2019).

68. Termine, J.; Eanes, E.; Conn, K. Phosphoprotein modulation of apatite crystallization. Calcif. Tissue Int. 1980, 31, 247-251. [CrossRef] [PubMed]

69. Iafisco, M.; Palazzo, B.; Falini, G.; Di Foggia, M.; Bonora, S.; Nicolis, S.; Casella, L.; Roveri, N. Adsorption and conformational change of myoglobin on biomimetic hydroxyapatite nanocrystals functionalized with alendronate. Langmuir 2008, 24, 4924-4930. [CrossRef]

70. Balas, F.; Manzano, M.; Horcajada, P.; Vallet-Regí, M. Confinement and controlled release of bisphosphonates on ordered mesoporous silica-based materials. J. Am. Chem. Soc. 2006, 128, 8116-8117. [CrossRef]

71. Huang, W.; Liu, W.; She, Z.; Wu, H.; Shi, X. Alendronate decorated nano hydroxyapatite in mesoporous silica: Cytotoxicity and osteogenic properties. Appl. Surf. Sci. 2011, 257, 9757-9761. [CrossRef]

72. Pascaud, P.; Errassifi, F.; Brouillet, F.; Sarda, S.; Barroug, A.; Legrouri, A.; Rey, C. Adsorption on apatitic calcium phosphates for drug delivery: Interaction with bisphosphonate molecules. J. Mater. Sci. Mater. Med. 2014, 25, 2373-2381. [CrossRef]

73. Kim, C.W.; Yun, Y.-P.; Lee, H.J.; Hwang, Y.-S.; Kwon, I.K.; Lee, S.C. In situ fabrication of alendronate-loaded calcium phosphate microspheres: Controlled release for inhibition of osteoclastogenesis. J. Control. Release 2010, 147, 45-53. [CrossRef] 
74. Åberg, J.; Brohede, U.; Mihranyan, A.; Strømme, M.; Engqvist, H. Bisphosphonate incorporation in surgical implant coatings by fast loading and co-precipitation at low drug concentrations. J. Mater. Sci. Mater. Med. 2009, 20, 2053-2061. [CrossRef]

75. Nancollas, G.; Tang, R.; Phipps, R.; Henneman, Z.; Gulde, S.; Wu, W.; Mangood, A.; Russell, R.; Ebetino, F. Novel insights into actions of bisphosphonates on bone: Differences in interactions with hydroxyapatite. Bone 2006, 38, 617-627. [CrossRef]

(C) 2019 by the authors. Licensee MDPI, Basel, Switzerland. This article is an open access article distributed under the terms and conditions of the Creative Commons Attribution (CC BY) license (http://creativecommons.org/licenses/by/4.0/). 